\title{
PRELIMINARY STRUCTURAL ANALYSIS OF THE WESTERN CURTAIN WALL OF ELMINA CASTLE, ELMINA, GHANA
}

\section{MARCOS N. DOS SANTOS ${ }^{1}$, SABASTIAN A. ABELEZELE ${ }^{1}$, KATHERINE A. KORSLUND $^{1 *}$, ROBERT T. CECIL ${ }^{2}$, SELMAN TEZCAN ${ }^{1}$, AND RENATO PERUCCHIO $^{3}$}

${ }^{1}$ Department of Mechanical Engineering

University of Rochester

Rochester, NY 14627, USA

e-mail: \{mnascim2, sabeleze, kkorslun, stezcan\}@u.rochester.edu

\author{
${ }^{2}$ Program of Archaeology, Technology and Historical Structures \\ University of Rochester \\ Rochester, NY 14627, USA \\ e-mail: rcecil@u.rochester.edu \\ ${ }^{3}$ Department of Mechanical Engineering and \\ Program of Archaeology, Technology and Historical Structures \\ University of Rochester \\ Rochester, NY 14627, USA \\ e-mail: renato.perucchio@rochester.edu
}

Keywords: Elmina Castle, Masonry Wall, Lateral Capacity, Non-Linear FE Explicit Analysis, Concrete Damaged Plasticity, Abaqus/CAE.

\begin{abstract}
Elmina Castle, built in 1482 by the Portuguese, was the first of a series of European trading bases along the west coast of Africa and served as a commercial outpost for over four centuries of trade. The structure was captured by the Dutch in 1637 and became a major hub for the Atlantic Slave Trade. The castle is currently a UNESCO World Heritage Site and a Ghanaian national museum. The building is constructed from a combination of mud-and lime-mortared rough-hewed sandstone masonry. The primary focus of the analysis is the western curtain wall, which faces the only side of the castle accessible by land. A flaring at the base of the curtain wall points to the likely presence of an additional tower located approximately midway along the length of the wall in early Portuguese times. Using a pushover analysis with nonlinear 3D FE under Abaqus/CAE explicit formulation, we assess the stability of the tower-wall system to determine if a historical earthquake could have caused the tower to collapse. During the Dutch occupation, a two-story building, brick vaulted at the ground level, was added along the entire curtain wall. Using 2D plane strain nonlinear models, we evaluate the structural capacity of this vaulted system, considering its sensitivity to the density and the thickness of the loose material above the vault as well as the compressive strength of the roughhewed sandstone masonry in the walls.
\end{abstract}




\section{INTRODUCTION}

Elmina Castle is the oldest permanent European structure in Sub-Saharan Africa, the first of a series of trading bases along Africa's West Coast. Built in 1482 as São Jorge da Mina by order of the Portuguese Crown, the castle served as an imposing commercial outpost for over four centuries of international trade. After the 1637 Dutch conquest, the castle became a major hub of the Atlantic Slave Trade involving Europe, Africa, and the Americas.

The castle is a UNESCO World Heritage Site and a national Ghanaian museum. The building, built on a rock mass projecting into the Atlantic Ocean, is the best-preserved example of early European masonry construction in Sub-Saharan Africa. Elmina Castle has been the object of a multidisciplinary field school conducted in Elmina, by the Archaeology, Technology, and Historical Structures Program of the University of Rochester in conjunction with the University of Ghana during the summers of 2017-2019.

\section{OBJECTIVES}

The goal of the paper is to provide a preliminary evaluation of possible changes in structural stability and lateral capacity of the western wall resulting from the various architectural changes introduced during the Portuguese and the Dutch occupation periods (1482 to 1872).

The primary focus of the analysis is the western curtain wall (shown in Figure 1a), which faces the only side of the castle accessible by land. Observation of this walk as currently standing shows that it was constructed using rough-hewed and lime mortars. The wall extends from an marked in Figure 1b, points to the likely pre
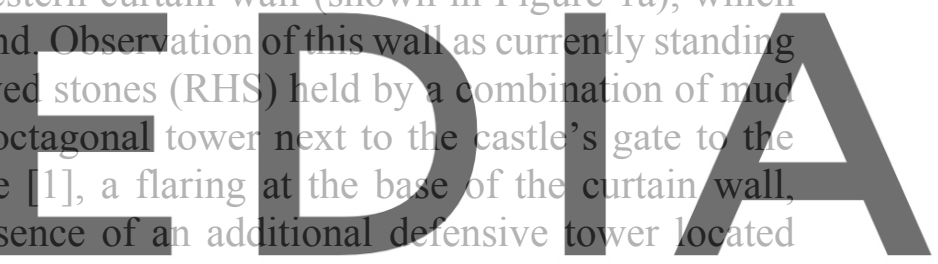

approximately midway along the length of the wall in early Portuguese times. This tower may

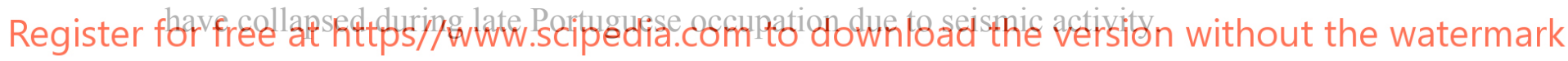

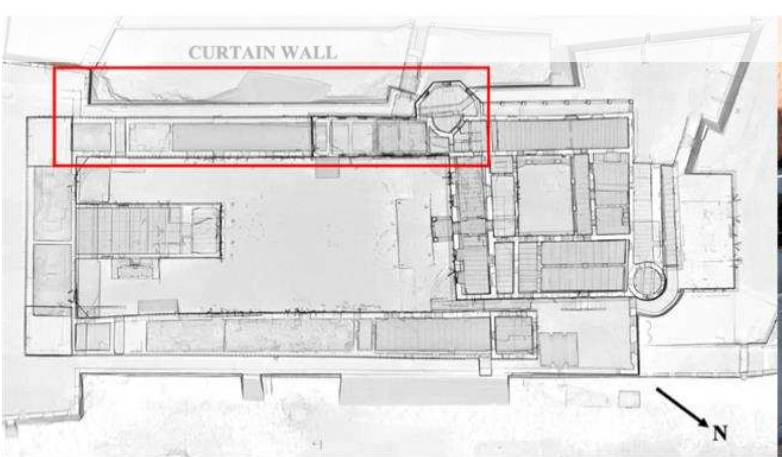

(a)

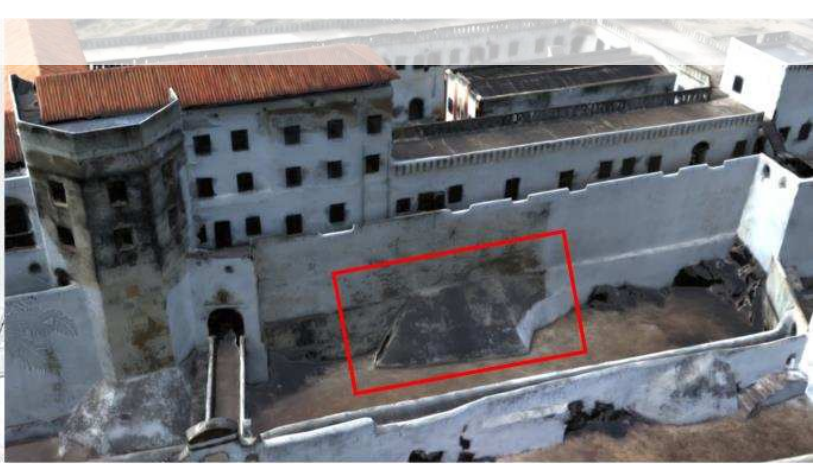

(b)

Figure 1: a) Plan view of Elmina Castle (western curtain wall highlighted), and b) aerial view facing the western curtain wall, with base flaring highlighted [2].

Our goal is to assess the stability of the wall-tower complex with a pushover analysis to determine if earthquakes could have been responsible for the collapse of this defensive tower. Models for these analyses were tested using nonlinear 3D finite element analysis (FEA) under 
the Abaqus/CAE Explicit formulation. During the Dutch occupation (1637-1872), the height and thickness of the curtain wall were increased, and a two-story building, brick vaulted at the ground level, was added along the entire curtain wall [1]. In this portion of the study, the objective is to perform a sensitivity analysis of $2 \mathrm{D}$ plane strain nonlinear models to evaluate the structural response based on assumed values for the density and thickness of the filler material as well as the compressive strength of RHS.

\section{METHODOLOGY}

Pushover analysis uses an incremental-iterative solution based on static equilibrium to solve for the response of the structure subjected to a monotonically increasing lateral load pattern $[3,4]$. In this study, all models are analyzed to find their collapse condition and related failure mechanism using gravitational loads based on the pushover analysis approach in Abaqus/CAE Explicit. During the pushover step, a uniform monotonically increasing horizontal acceleration is applied to the entire model until collapse conditions are reached.

\subsection{Evaluation of Collapse Conditions}

The time-evolution of strain energy (SE), kinetic energy (KE), and plastic dissipative energy (PD - due to plastic deformations simulating internal fractures) are used in order to identify the onset of local damage and its development into structural collapse (Figure 2a). Conditions of collapse can be reasonably characterized by three different collapse evaluation parameters: KE

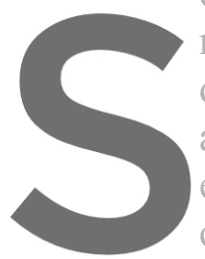
reaches $10 \%$ of the to dissipation energy cult a quasi-static behavio ensure that the analysis collapse. Hereafter, we
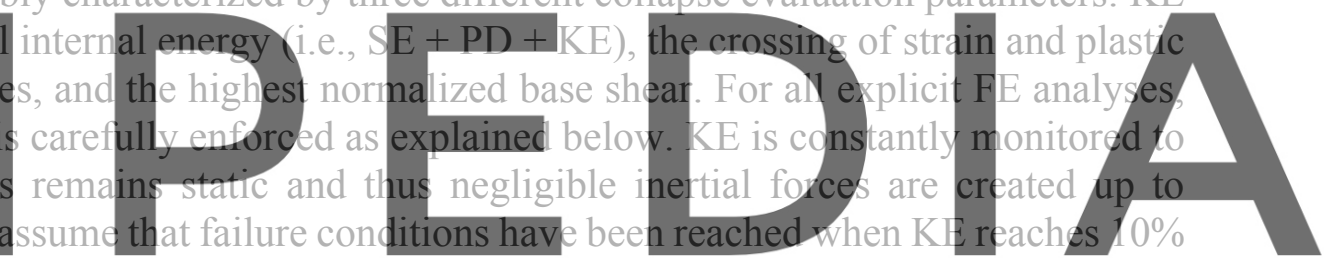

of the total internal energy (IE) of the system.

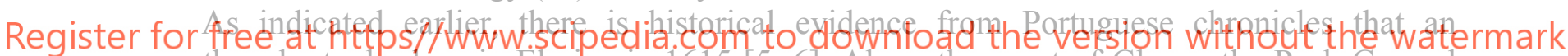
earthquake took place in Elmina in 1615 [5,6]. Along the coast of Ghana, the Peak Ground Acceleration (PGA) has been evaluated to be 0.026 - $0.2 \mathrm{~g}$ in 475 years [7]. We hypothesize that such an earthquake could have caused the collapse of the defense tower during the late Portuguese period. We also use the same seismic range to provide a preliminary assessment of the Dutch architectural changes introduced along the western wall since 1637 and which are still present in today's Castle.

The example of a single wall will be used to discuss the characterization of collapse conditions [8]. While gravity is applied during the first five seconds, only a vertical reaction is developed, as shown in Figure $2 \mathrm{~b}$. Thereafter, as a result of the inertial forces caused by the applied lateral acceleration, an equilibrating horizontal reaction force (basal shear) develops at the constrained boundary face. The linear ramp of lateral acceleration causes a nearly linear increase in the basal shear versus time while the vertical reaction holds constant (Figure 2b). At failure, both curves show a sudden decrease, indicating that the structure has lost the capability of resisting the lateral load. In this case, the mass of the wall has nearly completely separated from its base. Failure conditions are also determined from the curves shown in Figure 2c. Structural failure corresponds to the asymptotic growth of KE and PD and to the sudden drop in SE. Finally, for each analysis, results are shown in the form of capacity curves, such as the 
one shown in Figure 2c, which consist of base shear versus the displacement of a reference point. The normalized base shear is the ratio of the horizontal reaction forces to the weight of the model, expressed in terms of g. Further discussion is included in the paper by Sun et al. [8].

As for the collapse mechanism shown in Figure 2a, the black bands at the base of the wall represent areas where the plastic strain exceeds a threshold of 0.01 . Hereafter, the black bands shown in figures are interpreted as fractures that propagate through the quasi-brittle material.

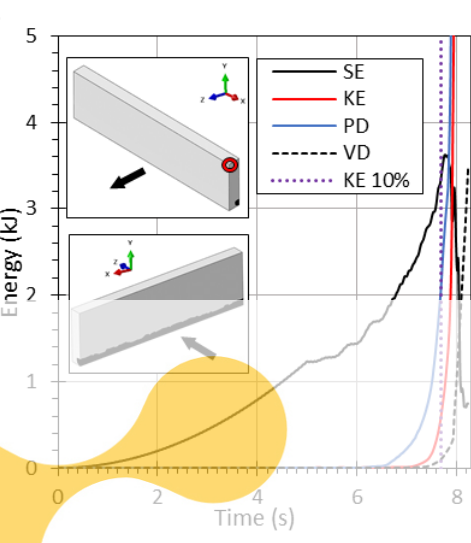

b.

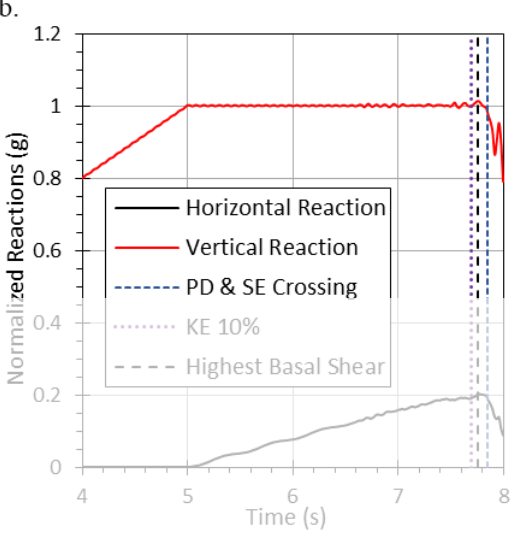

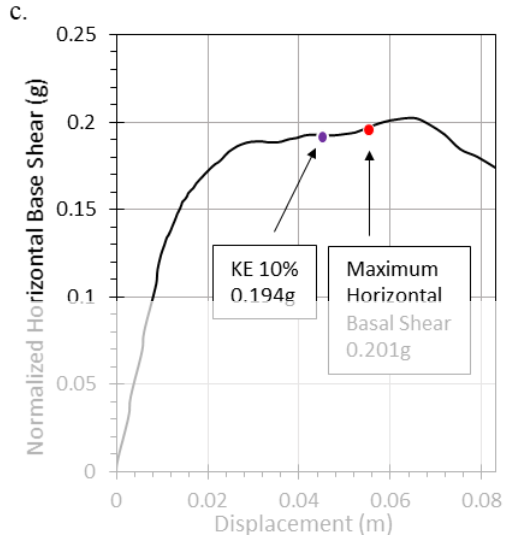

Figure 2: Single wall example: (a) energy curves versus time, (b) reaction forces versus time, and (c) capacity curve for reference point highighted in (a). In the a) insets, the black band indicates the fractured area

\subsection{Material properties}

In all the analyses, th

brittle materials [9]

together by mud and limine
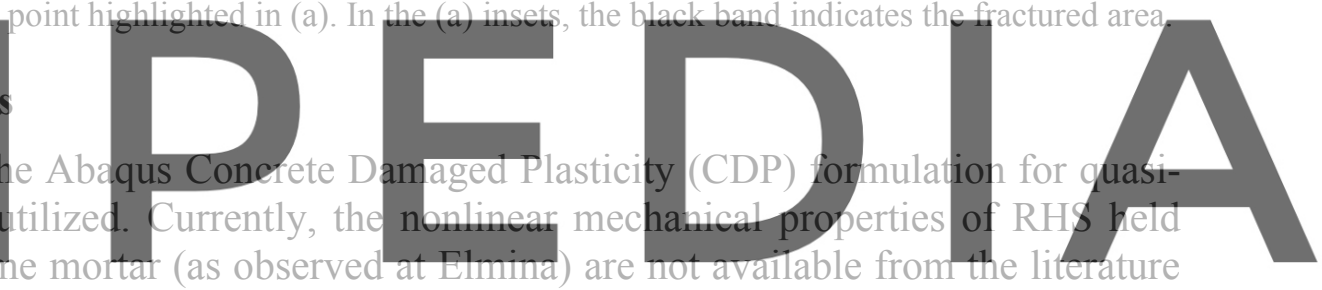

nor were we able to conduct any tests to evaluate them. Based on published experimental

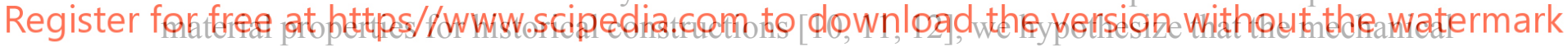

behavior of RHS falls in between that of adobe masonry and Roman pozzolanic concrete (PC).

PC serves as an upper bound while adobe provides a lower bound for the mechanical strength of RHS. For the analyses of the Portuguese architecture, the structural responses of both RHS and adobe were analyzed. To approximate the post-critical mechanical behavior of RHS, we scale down the nonlinear postcritical PC curves in tension and compression using the ratios of the tensile and compressive strength of RHS [12] to those of PC [10]. Thus, for compression, a ratio of $2 / 5 \mathrm{MPa}$ was used while a ratio of $0.07 / 0.5 \mathrm{MPa}$ was used for the tensile behavior.

Based on observations conducted in Elmina Castle and other European fortifications on the coast of Ghana, we use lateritic soil, here modeled as linear elastic, as filling material for the Dutch configurations. The general material properties adopted for the present study are shown in Table 1.

\begin{tabular}{|l|c|c|c|c|c|}
\hline \multicolumn{1}{|c|}{ Materials/Properties } & $\mathbf{E}(\mathbf{M P a})$ & $\boldsymbol{\gamma}$ & $\boldsymbol{\rho}\left(\mathbf{k g} / \mathbf{m}^{\mathbf{3}}\right)$ & $\mathbf{C o m}$ Str (MPa) & Tens Str (MPa) \\
\hline Adobe [13] & 123 & 0.2 & 1735 & 0.41 & 0.04 \\
\hline Rough-hewed Stone Masonry [10] & 1740 & 0.2 & 2000 & 2 & 0.07 \\
\hline
\end{tabular}


Marcos N. dos Santos, Sabastian A. Abelezele, Katherine A. Korslund, Robert T. Cecil and Renato Perucchio

\begin{tabular}{|l|l|l|l|l|}
\hline Lateritic Soil [16],[17] & 26 & 0.38 & 2200 & \\
\hline
\end{tabular}

Table 1: Mechanical properties of the materials.

General CDP parameters are shown in Table 2, where $\mathrm{fb} 0 / \mathrm{fc} 0$ is the ratio of initial equibiaxial compressive yield stress to initial uniaxial compressive yield stress, and $\mathrm{k}$ is a parameter related to the yield surface [13].

Table 2: General concrete damaged plasticity parameters.

\begin{tabular}{|l|c|c|c|c|c|}
\hline Materials/Properties & Dilation Angle $\left.\mathbf{(}^{\circ}\right)$ & Eccentricity & $\mathbf{f b 0 / f c 0}$ & $\mathbf{k}$ & Viscosity Param. \\
\hline Adobe and RHS Masonry [13] & 1 & 0.1 & 1.16 & 0.67 & $1 \mathrm{E}-8$ \\
\hline
\end{tabular}

\subsection{Models of the Portuguese architecture}

Figure 3a shows the earliest reliable representation of the Castle as drawn at the end of the Portuguese occupation (1637) by Frans Post [14]. This drawing serves as the basis for constructing the Portuguese architecture models. The view suggests the possible height of the eastern curtain wall, which we assume to be the same as the western curtain wall. This height was estimated to be $2 \mathrm{~m}$ based on features observable in the drawing and in today's Castle. The drawing also shows a circular tower next to the entrance of the castle, whose features are currently present and can also be found in the core of the current octagonal tower in the same location. This circular tower is used to estimate the dimensions of the tower in the models.

The Castle gate's dimensions would require a taller wall, which is confirmed by the trace of a $3.6 \mathrm{~m}$ wall (Eigure $3 \mathrm{~b}$ ), north of the hypothetical tower. A total of three geometries were
considered to assess the sensitivity of the structural capacity of the wall-tower complex to the
geometry and the materials. The first $3 \mathrm{D}$ configuration, in Figure $4 \mathrm{a}$, called Portuguese
consists of a $49.6 \mathrm{~m}$ long wall with a $1.3 \mathrm{~m}$ thickness. The wall is divided into two segnents,
north and south, by a circular tower. The position of the tower is based on the location of the flaring at the base approximately midway the length of the wall (Figure 1b), assumed to have

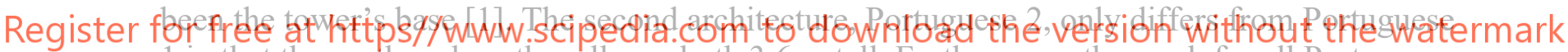
1 in that the north and south walls are both $3.6 \mathrm{~m}$ tall. Furthermore, the mesh for all Portuguese models consists of linear hexahedral elements (Figure 6a) fully constrained at the base and supported by rollers on the vertical end faces of the north and south walls to prevent motion of the faces along the $\mathrm{x}$ axis.

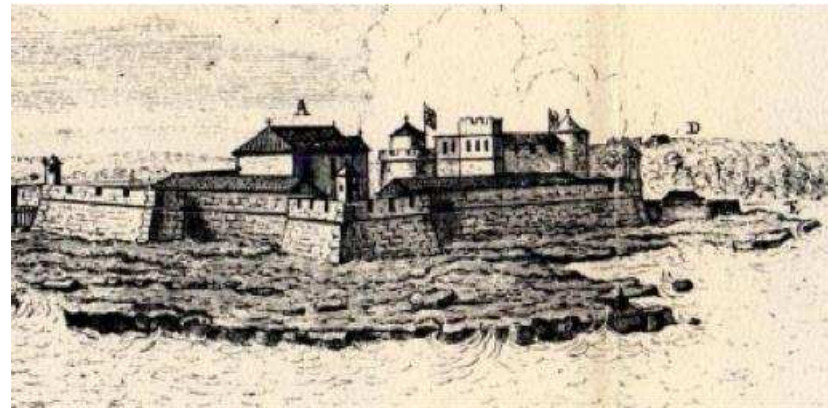

(a)

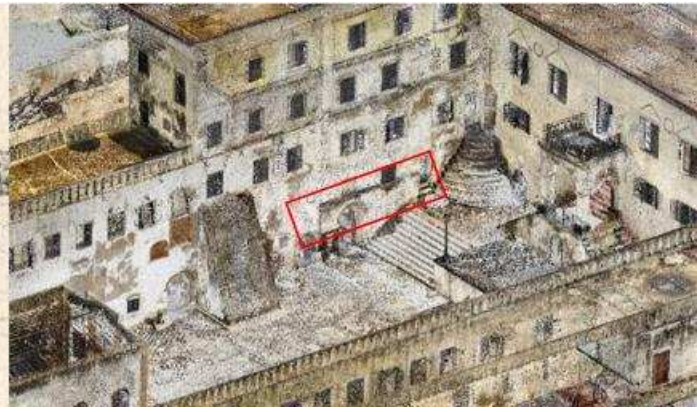

(b)

Figure 3: a) Drawing of Elmina Castle in 1637 by Frans Post [14] and b) aerial view of the entrance of Elmina Castle created with a point cloud [2]. The trace, boxed in red, points to a $3.6 \mathrm{~m}$ wall height. 
Considering that in typical $16^{\text {th }}$-century Portuguese military architecture the towers are supported by at least two perpendicular walls, e.g., the fort at Calicut in India [15], a third geometry is included to evaluate how the structural capacity would be affected by a wall abutting on the tower, perpendicular to the present curtain wall. The Portuguese 3 model consists of the same geometry as Portuguese 1 but with the addition of a perpendicular wall and
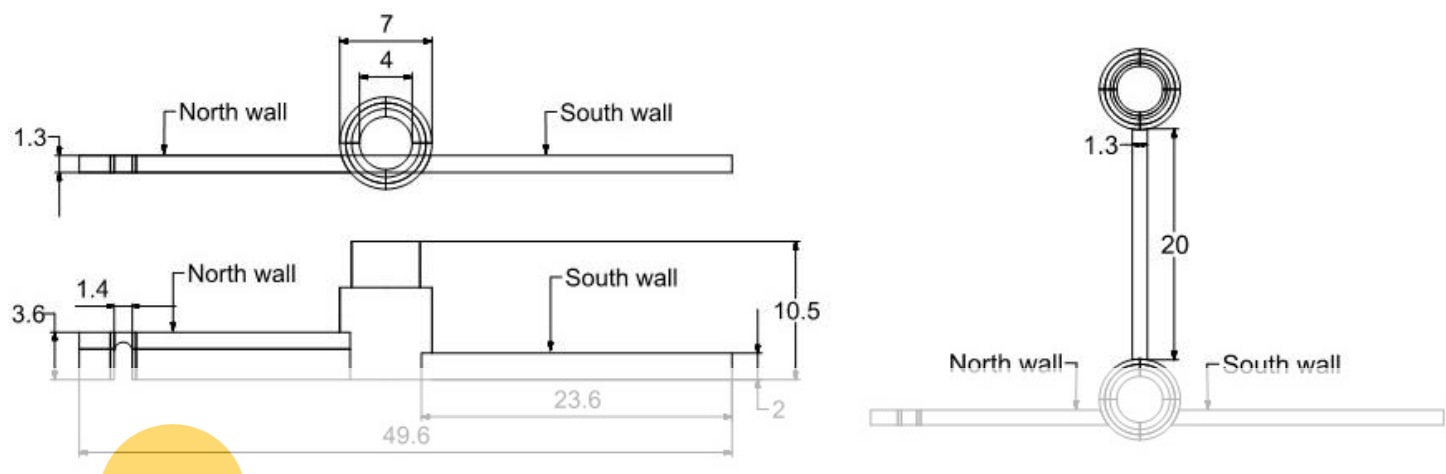

(a)

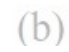

a tower at the end (Figure 4b). This third configuration was adopted purely for comparative reasons since there is no available archaeological evidence to support it.
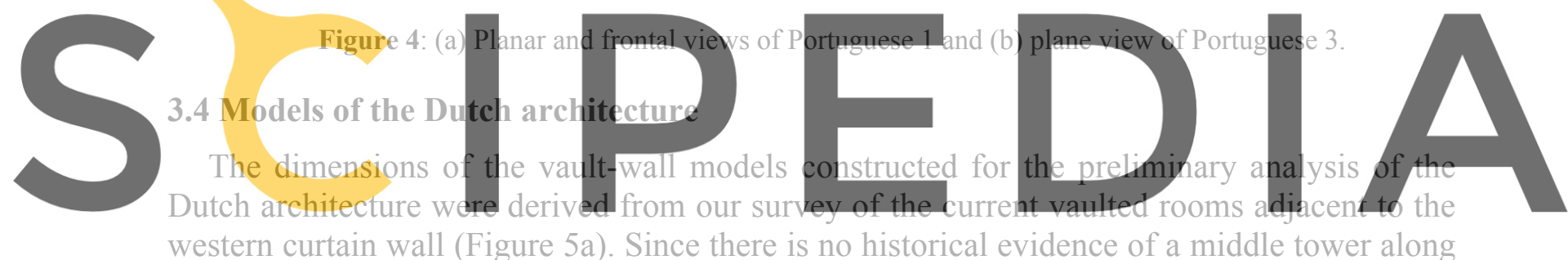
western curtain wall (Figure 5a). Since there is no historical evidence of a middle tower along

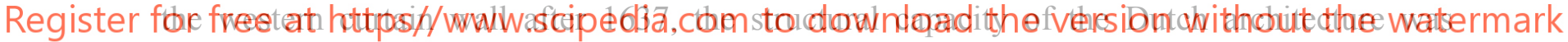
analyzed using nonlinear 2D plane strain models with a mesh of linear quadrilateral elements in Abaqus/CAE Explicit. The nature of the filler material present in between the outer and inner wall of the Dutch curtain wall and on top of the inner brick vault is currently unknown. Based on archeological evidence from other European forts along the coast of Ghana, we hypothesize that the filler material is either sand, with a density of $1200 \mathrm{~kg} / \mathrm{m}^{3}$ or $1600 \mathrm{~kg} / \mathrm{m}^{3}$, or lateritic soil, with a density of $2200 \mathrm{~kg} / \mathrm{m}^{3}$. In all models, the filler material was modeled as linear elastic.

There is evidence that the original floor above the vault was lower than the present one. A map from 1774 shows a stairway on the interior western wall that corresponds to the location of several filled-in openings still present in the wall under consideration. The position of the stairway and the height of the openings from the ground suggest that the original floor was 40 $\mathrm{cm}$ lower than the present one. Thus, to evaluate the sensitivity of the lateral capacity of the vaulted system to the height of the loose material above the vault, we consider the following values of the t parameter shown in Figure $5 \mathrm{~b}: 100 \mathrm{~cm}, 60 \mathrm{~cm}$, and $20 \mathrm{~cm}$. Moreover, considering a sensitivity study of the structural capacity to the compressive strength (CS) of RHS, we test seventeen models (Table 3 ) in which the three parameters (filler density, $t$, CS) are varied.

Due to the lack of data on the dimensions and composition of the curtain wall, a simpler model of the actual geometry with no curtain wall is used in this preliminary analysis (Figure 
$5 b)$ before running a full analysis of the vaulted building and curtain wall. The simpler geometry chosen for the analysis allows for a detailed study of the sensitivity of the structural capacity to the unknown parameters. Considering that structural damage associated with the Dutch

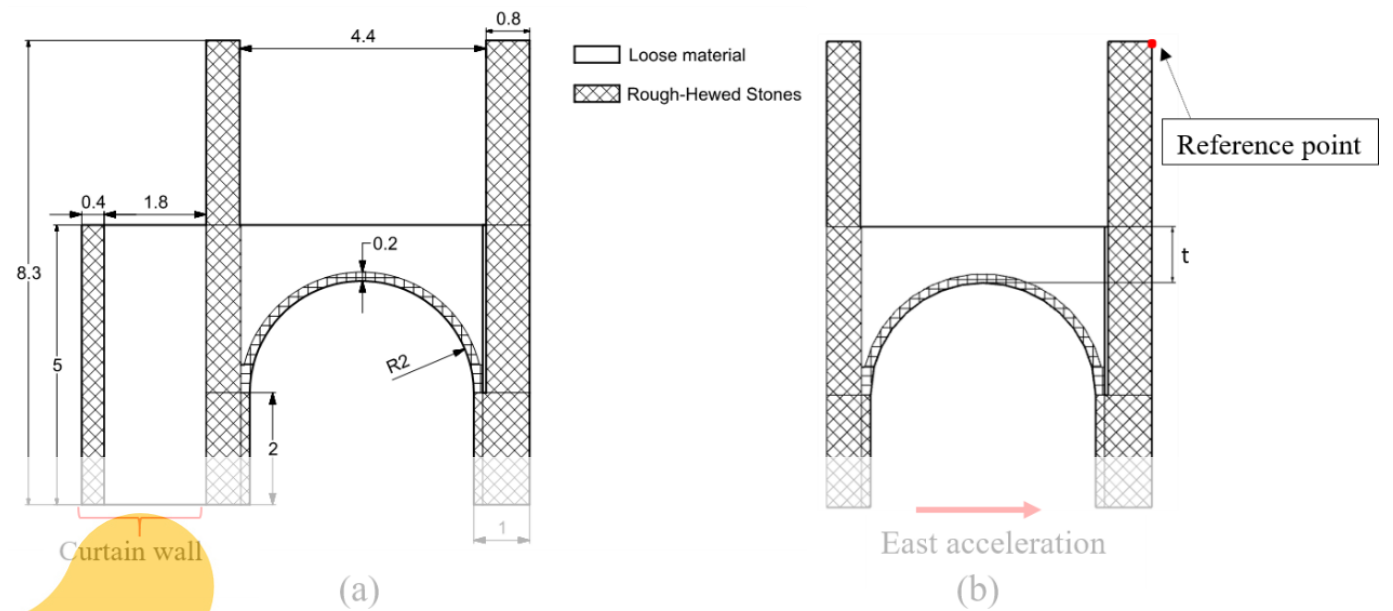

geometry has not been observed, the lateral capacity of the structure is tested against the local seismic demand with a PGA range of $0.026-0.2 \mathrm{~g}$ [7] to verify whether the numerical results are plausible. For the analysis of a similar Dutch vaulted architecture along the east curtain wall of Elmina castle see Sun et al. [8].
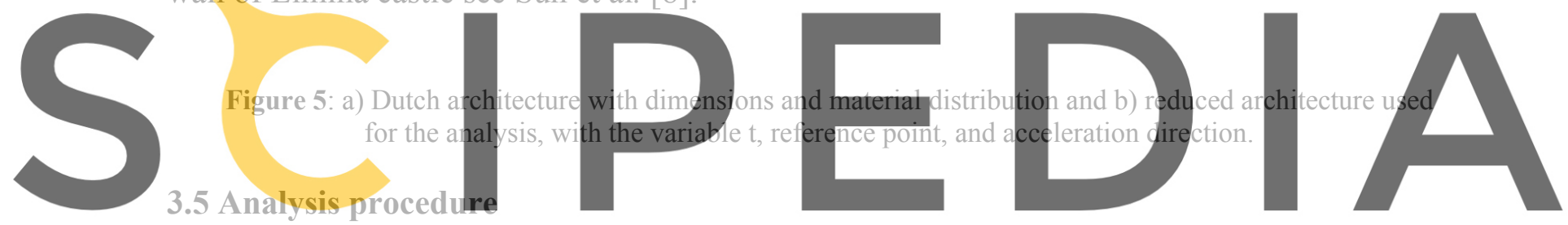

In all cases, the pushover analysis is conducted in quasi-static conditions.until collapse. In

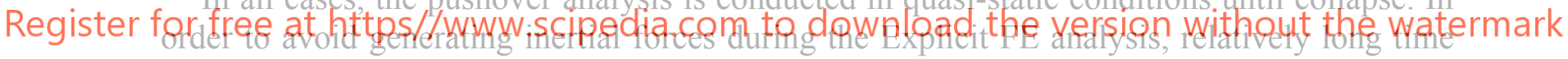
intervals are used for the gradual application of gravitational loads followed by lateral accelerations. For the Portuguese configurations, gravity is applied over two seconds as a vertical acceleration increasing linearly over time from 0 to $1 \mathrm{~g}$. This is followed by a uniformly distributed lateral acceleration applied to the model over twenty seconds for the Portuguese 1 model and eight seconds for the Portuguese 2 and 3 models, increasing linearly until collapse conditions are reached (shown in Figure 6b, the moment at which KE reaches $10 \%$ of IE for a Portuguese 1 model).

All Portuguese models were tested with lateral acceleration perpendicular to the wall in both east and west directions, where west points towards the exterior of the curtain wall. For all models, acceleration in the west direction resulted in the lowest lateral capacity. Therefore, only the results of the models with acceleration in the west direction will be discussed. For the construction of the capacity curves, displacements for each model are measured at the reference point shown in Figure 6a.

For the Dutch architecture, the reference point from which all horizontal displacements are measured as well as the direction of the applied lateral acceleration are shown in Figure 5b. The acceleration in this direction resulted in the lowest lateral capacity. Gravity here also is applied 
over two seconds as a vertical acceleration increasing linearly over time from 0 to $1 \mathrm{~g}$. Application of gravity is then followed by a uniformly distributed lateral acceleration applied to the model over ten seconds for all Dutch models, increasing linearly until collapse conditions are reached.

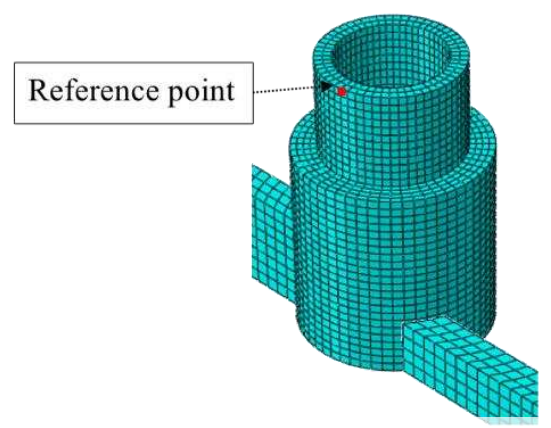

(a)

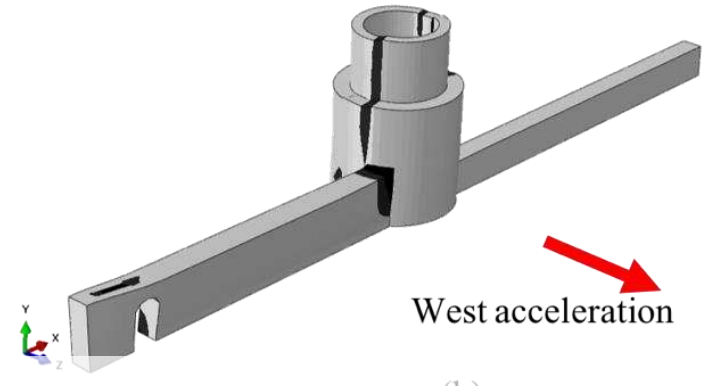

(b)

Figure 6: (a) Mesh of Portuguese 1 with reference point and (b) damage status and deformation of Portuguese 1 (RHS, 15 per) at failure (KE at 10\% of IE). Black bands indicate fractures.

\section{RESULTS AND DISCUSSION}

\subsection{Analysis of the Por \\ This section focuses \\ respect to basic architec
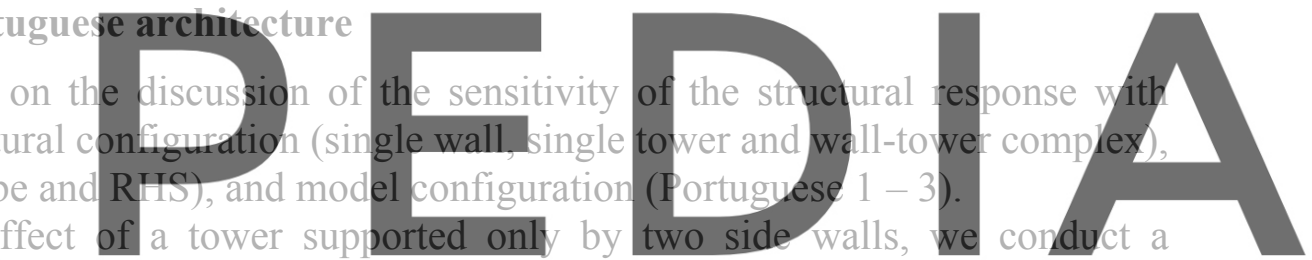 \\ To understand the}

comparative test involving a single wall, a single tower, and the combination of the two

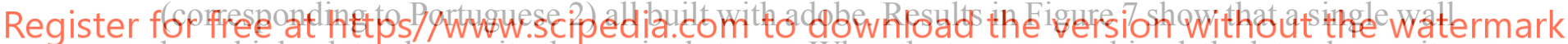

has a higher lateral capacity than a single tower. When the two are combined, the lateral capacity

of the structure decreases to a third of that of the single wall. For the combined model, the tower

reaches collapse conditions after its upper part splits vertically into two (Figure 7).

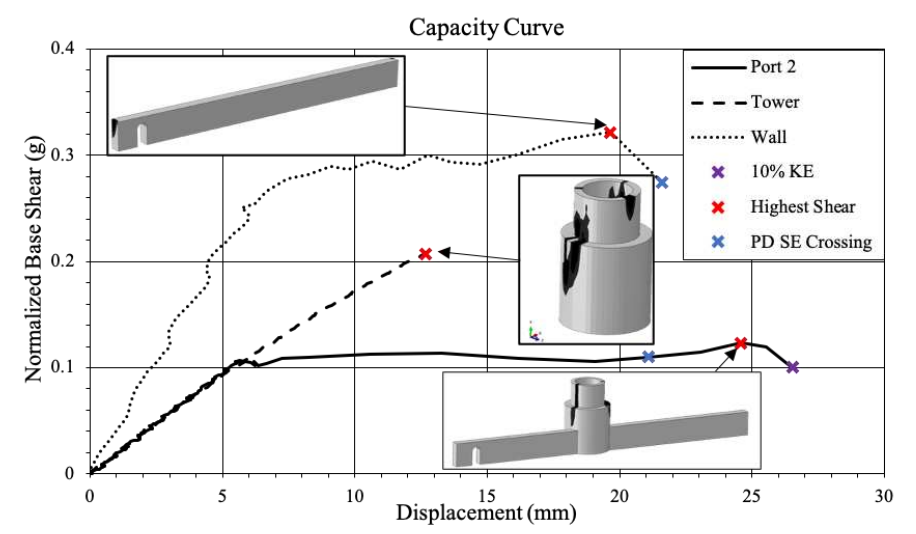

Figure 7: Curve for lone tower, single wall, and combination of tower and wall (adobe). Black bands indicate fractures. 
For the sensitivity due to changes in material properties, models built with RHS have a higher lateral capacity as compared to those built with adobe. The lateral capacities of the Portuguese 1 and 3 models with RHS are about five times the lateral capacities of the same configurations built with adobe (Figures 8 and 9). The collapse of the Portuguese 1 and 2 adobe models involves the vertical splitting of the tower (Figures 8-2 and 7, respectively). The failure mechanism of the RHS model is characterized by the separation at the juncture of the intact tower and the walls (Figure 8-1) as the tower rotates as a solid body. The vertical fractures developed at the upper part of the adobe towers, directly above the walls (Figure 8-2), are due to the relatively lower tensile strength of adobe.
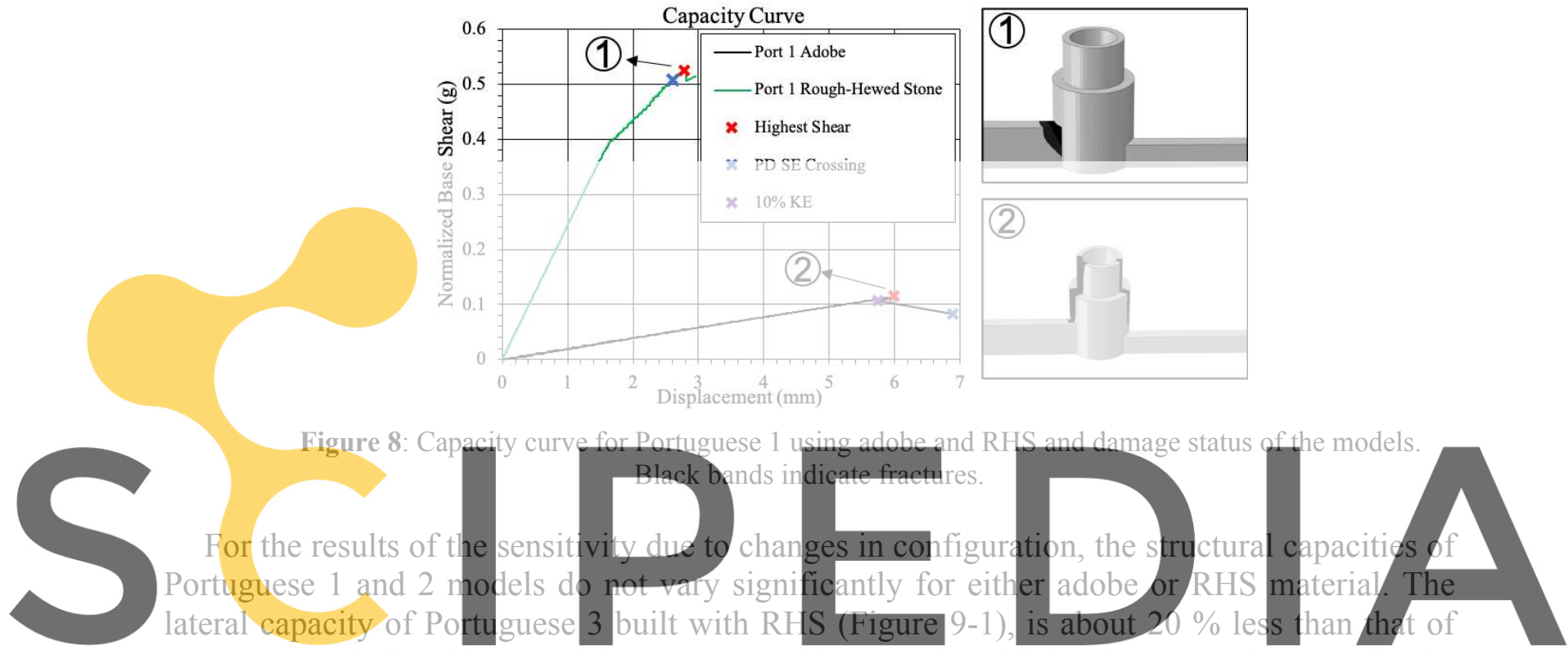

Portuguese 1 built with RHS (Figure 8-1). In this case, the additional tower and perpendicular

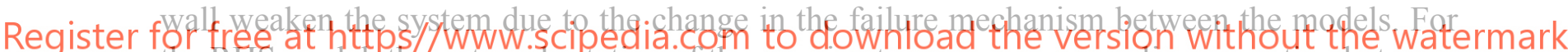
the RHS model, the outward rotation of the massive tower causes an earlier separation between

the tower and the perpendicular wall (Figure 9-1). For the adobe model (Figure 9-2), the perpendicular wall further constrains the tower, and rotations are minimized. However, the additional tower splits vertically, developing fractures above the perpendicular wall as it rotates.

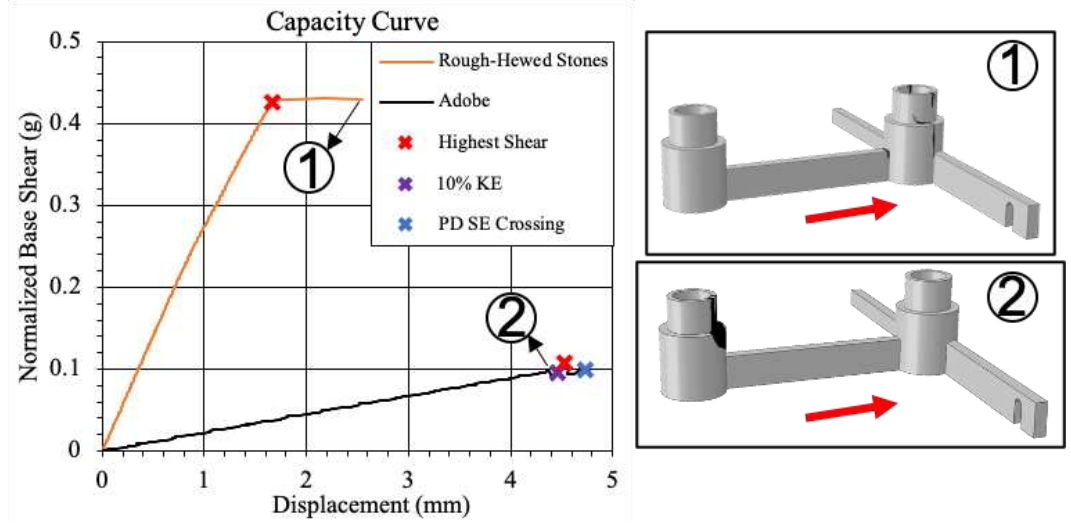

Figure 9: Capacity curve for Portuguese 3 built with adobe and RHS and damage status of the models (in black). 


\subsection{Preliminary analysis of the Dutch architecture}

Figure 10a (1 and 2) shows the damage patterns observed for one of the seventeen models built for this study. This model, which corresponds to Model 5 in Table 3, was chosen as it exhibits the general mechanical behavior observed for all models. The model has a thickness $t$ $=100 \mathrm{~cm}$, a compressive strength of RHS of $3 \mathrm{MPa}$ and filler density of $1600 \mathrm{~kg} / \mathrm{m}^{3}$. The capacity curve from the analysis suggests a structural response to lateral acceleration that barely satisfies the seismic demand reported for the region $(0.026-0.2 \mathrm{~g})$ [7]. Since the upper part of the walls does not show signs of plasticity, they have been omitted to simplify the illustration of the damage status sequence of the model as shown in Figure 10a. Towards the end of the application of gravity, the filler material in combination with the lateral thrust of the vault imposes sufficient lateral pressure onto the left wall to cause fractures at the base (Figure 10a1). As damage progresses to stage 2, vertical fractures develop on the left wall, indicating the crushing of the material. Horizontal damage also develops at the base of the right wall due to the bending condition imposed by the increased lateral acceleration.

As shown in the damage status sequence in Figure 10a, the outward rotation of the walls increases as a result of the increased lateral acceleration. As the horizontal fracture propagates, a hinge develops at the base of the right wall, causing a concentration of compressive stresses on the far-right side. At this point of the analysis, in addition to a vertical fracture due to crushing of RHS, rotational hinges also form on the vault. Stage 2 captures the instant at which KE reaches $10 \%$ of IE - corresponding to the total collapse of the structure.

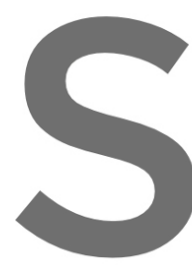

The results from the sens demonstrate that structural Considering that model lateritic soil with a densit vaults since the structur
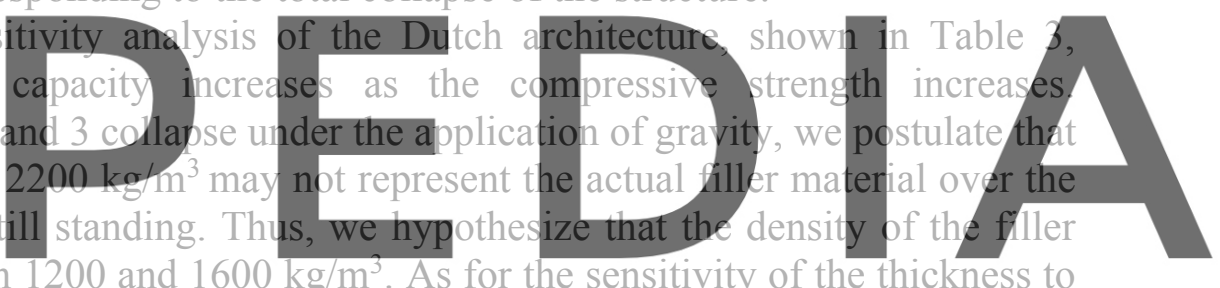
material should range between 1200 and $1600 \mathrm{~kg} / \mathrm{m}^{3}$. As for the sensitivity of the thickness to

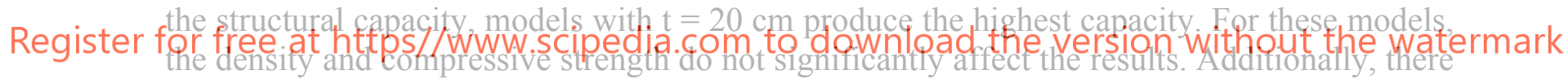
is a marginal difference in capacity between the models with $\mathrm{t}=60 \mathrm{~cm}$ and $\mathrm{t}=20 \mathrm{~cm}$.

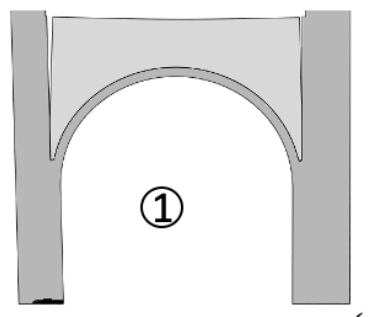

(a)

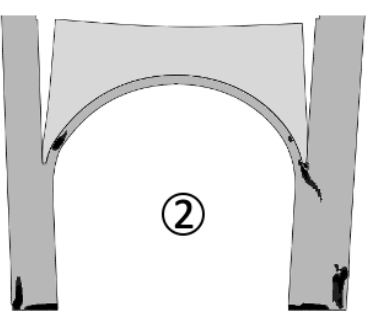

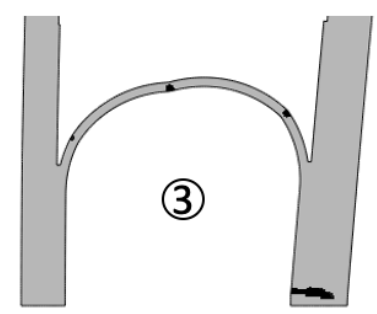

(b)

Figure 10: (a) Damage evolution of one of the Dutch architecture models and (b) analysis without filler material. The upper part of the walls has been truncated to show only the structural elements where damage occurs. Black bands indicate fractures.

An additional analysis of the Dutch architecture without filler material on the extrados of the vault is performed. The final stage of the damage evolution is shown in Figure 10b. Considering $10 \% \mathrm{KE}$, maximum base shear, and PE and SE crossing, the critical $\lambda$ was found to be 0.095 . 
This marks a $20 \%$ increase in capacity from the models with the same filler material $(\lambda=0.08)$. Clearly, further work is necessary to properly characterize the behavior and mechanical properties of this filler material due to its significant impact on the behavior of the system.

Table 3: Setup and results of the Dutch architecture sensitivity analysis.

\begin{tabular}{|c|c|c|c|c|}
\hline Model & \multirow{2}{*}{$(\mathbf{c m})$} & $\boldsymbol{\rho}\left(\mathbf{k g} / \mathbf{m}^{\mathbf{3}}\right)$ & $\left.\boldsymbol{\sigma}_{\mathbf{C}} \mathbf{( M P a}\right)$ & $\boldsymbol{\lambda}(\mathbf{g})$ \\
\hline $1|2| 3$ & \multirow{3}{*}{100} & 2200 & $2.0|3.0| 5.0$ & Fails under gravity \\
\cline { 1 - 3 } & & 1600 & $2.0|3.0| 5.0$ & $0.00|0.08| 0.09$ \\
\cline { 4 - 5 } $4|5| 6$ & 1200 & $2.0|3.0| 5.0$ & $0.08|0.07| 0.07$ \\
\hline $7|8| 9$ & \multirow{2}{*}{60} & 1600 & $2.0 \mid 3.0$ & $0.07 \mid 0.08$ \\
\cline { 4 - 5 } & & 1200 & $2.0 \mid 3.0$ & $0.08 \mid 0.09$ \\
\hline $10 \mid 11$ & \multirow{2}{*}{20} & 1600 & $2.0 \mid 3.0$ & $0.09 \mid 0.10$ \\
\hline $14 \mid 13$ & 1200 & $2.0 \mid 3.0$ & 0.10 \\
\hline $16 \mid 17$ & & & & \\
\hline
\end{tabular}

\section{CONCLUSIONS AND FURTHER WORK}

The results from the analysis of the Portuguese architecture demonstrate the destabilizing effect under seismic conditions of a tower sitting astride the western curtain wall. Under the assumption of a structure built with adobe-like material in early Portuguese times, the tower and the walls are likely to have collapsed under the lateral acceleration of the earthquake historically documented in the early $1600 \mathrm{~s}[5,6]$. Under those conditions, it is logical to expect that the entire western curtain wall would have been rebuilt by the Portuguese without the tower, a solution maintained by the Dutch and subsequently by the British until present time.

All analyses of the Dutch architecture have critical capacities below $0.10 \mathrm{~g}$. These are relatively low values, for which a seismic input with the range $0.026-0.2 \mathrm{~g}$ could be critical to the stability of the structure. Thus, the results of the Dutch modifications in terms of the introduction of the vaulted structure and substantial filler material thickening are problematic, since they appear to indicate a marginally stable structural configuration, already approaching a highly damaged condition under relatively minimal lateral acceleration. Considering that this new configuration has been around for more than two hundred and fifty years and appears to be in a good state of conservation, these unstable configurations are questionable and suggest the presence of either a less dense filler material or of a stone masonry of higher compressive strength or both.

Looking at the data on which the present model is based, the following issues can be identified: (a) The actual composition of the walls used in the Dutch models is unknown, and (b) the actual composition of the filler material resting on the extrados of the vault is also unknown. Its composition and density adopted in this preliminary work are based on observations made in another sector of Elmina Castle.

Future work should address the above issues experimentally, through in-situ study of the materials and the wall composition, and numerically, through a systematic sensitivity analysis.

Acknowledgements. We thank Michael Jarvis and Christopher Muir for their contributions to the surveying of Elmina Castle. Louisa Anderson helped us in establishing the early Portuguese architecture. Selman Tezcan provided guidance with the nonlinear numerical modeling. The 
David T. Kearns Center of University of Rochester provided support through summer research scholarships to Kate Korslund and Marcos dos Santos. Jiacheng Sun helped translate a source from Chinese to English.

\section{REFERENCES}

[1] Lawrence, A.W. Trade Castles and Forts of West Africa. London: Jonathan Cape, (1963). [2] Jarvis, M. Personal communication. Elmina Castle, FARO Laser Scans and UAV Aerial Image Capture. University of Rochester, Department of History, (2019).

[3] Kunnath, S. K. Identification of Modal Combination for Nonlinear Static Analysis of Building Structures. Computer-Aided Civil and Infrastruc. Eng. (2004), 19, pp. 246-259.

[4] Pinho, R. Using Pushover Analysis for Assessment of Buildings and Bridges. In: Pecker A. (Eds.): Advanced Earthquake Engineering Analysis. CISM International Centre for Mechanical Sciences, vol 494. Springer, Vienna, (2007).

[5] Ambraseys, N. N., and Adams, R. D. Seismicity of West Africa. Annales Geophysicae, Vol. 4B, No. 6, (1986), pp. 679-702.

[6] Vogt, J. Portuguese Rule on the Gold Coast: 1469-1682. Athens: GA, (1979).

[7] Ahulu, S. T., Danuor, S. K., and Asiedu, D. K. Probabilistic seismic hazard assessment of southern part of Ghana. Journal of Seismology, Vol. 22, (2017), pp. 539-557.

[8] Sun, J., Tezcan S., Perucchio, R. The Structural Function of the East Curtain Wall of Elmina Castle, Elmina, Ghana. $12^{\text {th }}$ International Conference on Structural Analysis of Historical Constructions, (2020).

[9] Abaqus Analysis User's Manual Simulia, v.6.6, Damaged plasticity model for concrete and other quasi-brittle materials, Dassault System Corporation, available online, (2006).

[10] Brune, P.F. The Mechanics of Imperial Roman Concrete and the Structural Design of Vaulted Monuments. Doctoral Thesis: Department of Mechanical Engineering, Arts, Sciences and Engineering, University of Rochester, (2010).

[11] Aguilar, R. et Al. Structural and geotechnical engineering assessment of Huaca de la Luna - A massive earthen Moche culture pyramid in Norther Peru. Journal of Cultural Heritage, Vol. 34, November-December (2018), pp. 83-94.

[12] Angelillo, M., Lourenco, P.B., Milani, G. Masonry behavior and modelling. In: M. Angelillo (Ed.): Mechanics of Masonry Structures. CISM International Center for Mechanical Sciences, Vol 551. Springer (2014) pp 1-26.

[13] Tarque, N. Numerical Modelling of the Seismic Behavior of Adobe Buildings. PhD dissertation, Universitá degli Studi di Pavia, Italy (2011), pp. 136.

[14] Post, F. São Jorge da Mina. Dutch National Archive (1637).

[15] Correia, G. Portuguese outpost, Calicut, 16th century, Lendas da India. Royal Academy of Sciences of Lisbon, (1858-1866).

[16] Chen L.J., Dai Z.H., Liu Z.W. Three-dimensional nonlinear finite element analysis of soft soil excavation engineering considering K0 consolidation. Rock Soil Mech (2011) 32(12): 3796-3804 (in Chinese).

[17]Fall, M., Sarr, D., Ba, M. Evolution of lateritic soils geotechnical parameters during a multicyclic OPM compaction and correlation with road traffic. Geomaterials 1 (2011), pp. 29-69.

[18] Abaqus Analysis User's Manual Simulia v.6.14.6.3.3 Explicit dynamic analysis. Dassault System Corporation, Providence, RI (2018). 
Marcos N. dos Santos, Sabastian A. Abelezele, Katherine A. Korslund, Robert T. Cecil and Renato Perucchio

[19] The Hague, Collection Foreign Maps Leupe, number access 4.VEL, inventory number 779A, Dutch National Archive (1774). 